
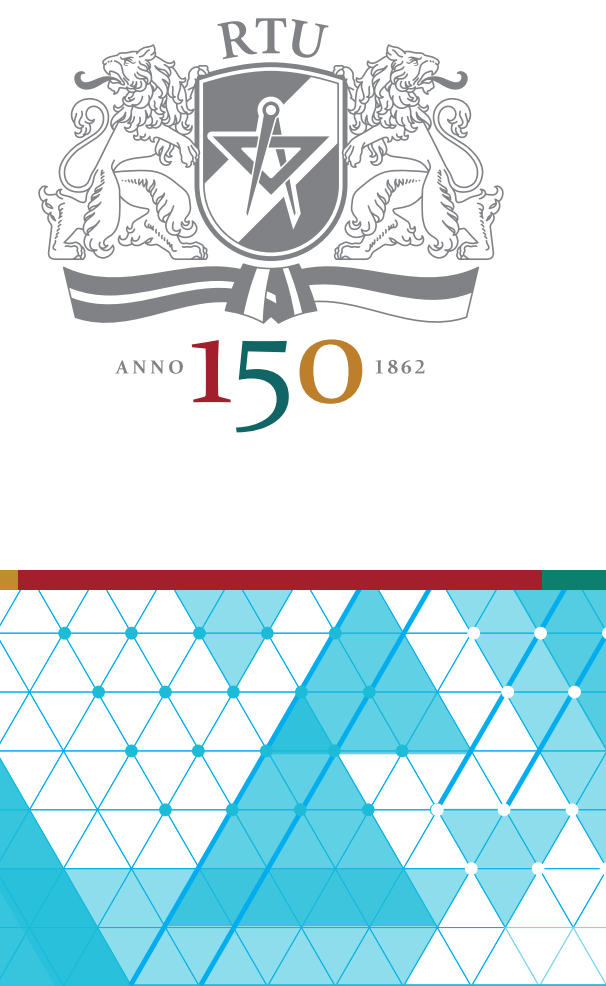

11-12 October 2012, Riga

Riga Technical University 53rd International Scientific Conference

Dedicated to the $150^{\text {th }}$ Anniversary and The 1 st Congress of World Engineers and Riga Polytechnical Institute / RTU Alumni

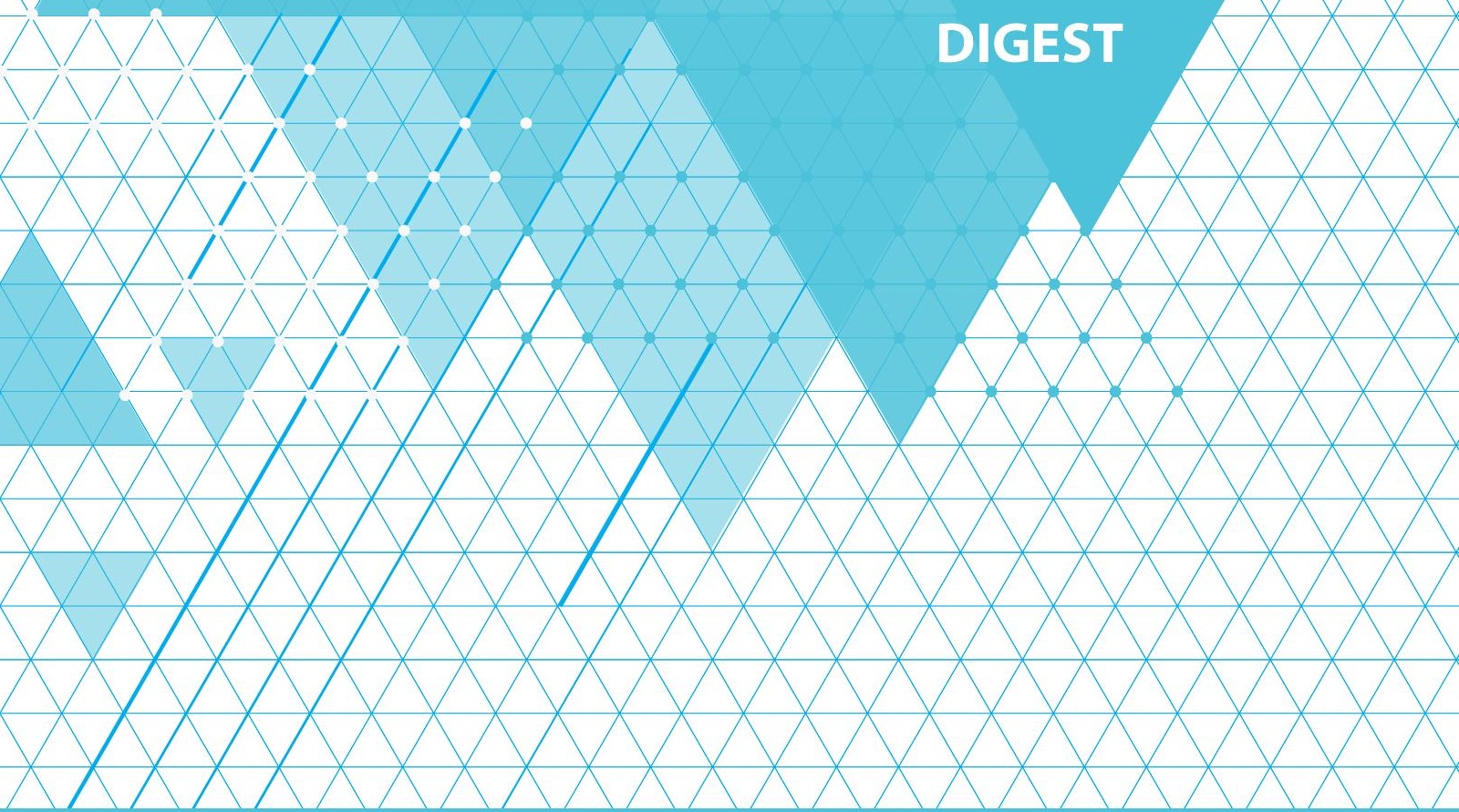




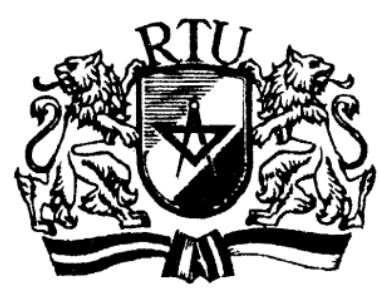

\section{RIGA TECHINICAL UNIVERSITY $53^{\text {rd }}$ INTERNATIONAL SCIENTIFIC CONFERENCE DEDICATED TO THE $150^{\text {th }}$ ANNIVERSARY AND THE $1^{\text {st }}$ CONGRESS OF WORLD ENGINEERS AND RIGA POLYTECHINICAL INSTITUTE / RTU ALUMINI}

11-12 October 2012

Rīga, Latvija 


\title{
CT Dose Index Test with Standard Phantoms
}

\author{
Nelda Kreislere (Riga Technical University) and Aldis Balodis (Riga Technical University)
}

Keywords - CT dose index (CTDI ), head and body phantom, dose distribution, uncertainty.

\section{INTRODUCTION}

The aim of study is to find out how measuring the absorbed dose depends on the different axial scanning technologies and how they affect the measured value using standard dose test method with CT dose head and body phantoms.

Computed tomography one of the most pressing tasks is to dose reduction. [1] Parameters associated with received radiation doses and depend on the hardware technical support are: slice thickness, the distance between slice, interlayer, examination region, exposure factor and gantry tilt. Image quality and radiation dose affect patient received dose in examination.

Computed tomography manufacturers given base CT Dose Index (CTDI) values are highly dependent on scanning parameters and characteristics of the scanner. Therefore image quality and radiation dose affect patient received dose in examination and it may not always be assessed quantitatively, when measured with CT dose test phantoms. However, to achieve this objective requires more and more new approaches for the determination of the dose rate $\mathrm{CT}$, and in assessing the information provided by different manufacturers, firstly, of the CT dose index (CTDI), that can compare with the standard methods and the assessment of the patient dose. [2]

To determinate CT dose index in CT dose phantom there are nothing says about the limits of the scan length of the phantoms, not exceed the permissible uncertainty related to possible scatter of the phantom side the edge.

The aim of study was to find out how during measuring the absorbed dose in phantoms depends on the different axial scanning technology and the changing nature of the measured value over all phantom length using standard CT phantoms and as well clarify difference between measured weighted CT dose index and the given manufacturer (base) values.

\section{MATERIALS AND METHODS}

The measurements were made using single slice CT scanner Siemens Somatom AR.SP, pencil type ionization chamber with active length $100 \mathrm{~mm}$, which were connect with test device Victoreen 4000+, the CT Dose Phantom, which consists of $15 \mathrm{~cm}$ thick solid PMMA disks measuring $16 \mathrm{~cm}$ (head) and $32 \mathrm{~cm}$ (body) in diameter.

All measurements were made on the basis of IEC 60601-244 [3], measuring the absorbed dose, and then calculating the CT dose index.

The radiation dose profile along a line perpendicular to the plane of a single axial CT scan shows a peak where the primary beam slices through the CTDI phantom. A CTDI100 value is obtained if integration limits of $\pm 50 \mathrm{~mm}$ are used (1).

$$
C T D I_{100}=D \cdot K_{1} \cdot \frac{L}{\text { slice }}
$$

where D- measured dose (mGy), $\mathrm{K}_{1}$-calibration factor, Lionization chamber- $100 \mathrm{~mm}$ active length $(\mathrm{mm})$, slice $(\mathrm{mm})$.
Scanning was made with a variety of slice thicknesses 2,3 , $5,10 \mathrm{~mm}$ over the entire length of the ionization chamber, with the same table feed.

\section{RESULTS AND DISCUSSION}

Equable absorbed dose distribution was obtained during measurements when ionization chamber was positioned freely in air without other absorbent. We found that the equable measurements can be made anywhere in the ionization chamber (f.v. Fig.1).

However the results obtained using $\mathrm{CT}$ phantoms show that the CT dose index $\left(\mathrm{CTDI}_{100}\right)$ measured with a $100 \mathrm{~mm}$ long active measuring length phantom makes 30 - 35\% uncertainty in the head phantom (Fig.2) and up to $50 \%$ uncertainty in the body phantom (f.v. Fig.3), compared to the middle of the phantom measurements with a measuring $100 \mathrm{~mm}$ long section ends.

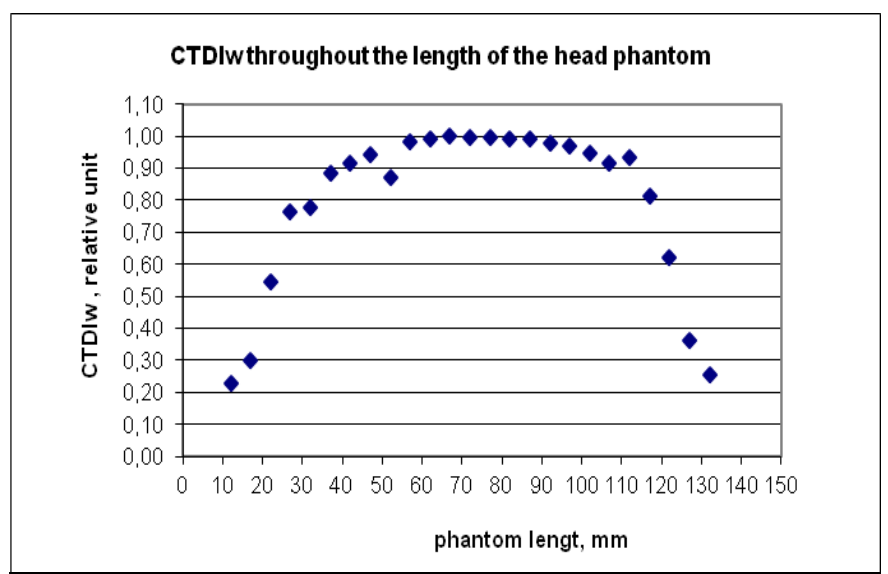

Fig.2 Absorbed dose distribution of the head phantom at the slice thickness and table feed of $5 \mathrm{~mm}$, max value of CTDIw $=82,50 \mathrm{mGy}$.

\section{CONCLUSION}

Study has shown that the absorbed dose distribution uncertainty for measurements along the length does not exceed $5 \%$ of the head phantom. A phantom of $40 \mathrm{~mm}$ mid-range and a $45 \mathrm{~mm}$ body phantom could be applied.

\section{REFERENCES}

[1] Siemens launches dose reduction initiative at http://medicalphysicsweb.org/cws/article/research/43089

[2] Xinhua Li, Da Zhang and Bob Liu (2011) A practical approach to estimate the weighted CT dose index over an infinite integration length. Physics in Medicine and Biology 562011 pp. Volume 56, Issue 18: 5789-5803

[3] IEC 60601-2-44 Medical electrical equipment - Part 2-44: Particular requirements for the basic safety and essential performance of X-ray equipment for computed tomography (2009) 